\title{
TRPC5-eNOS Axis Negatively Regulates ATP-Induced Cardiomyocyte Hypertrophy
}

\author{
Caroline Sunggip ${ }^{1,2+}$, Kakeru Shimoda ${ }^{1,3+}$, Sayaka Oda ${ }^{1,3+}$, Tomohiro Tanaka1, \\ Kazuhiro Nishiyama ${ }^{4}$, Supachoke Mangmool'5, Akiyuki Nishimura ${ }^{1,3}$, \\ Takuro Numaga-Tomita ${ }^{1,3}$ and Motohiro Nishida ${ }^{1,3,4 *}$
}

${ }^{1}$ Division of Cardiocirculatory Signaling, Creative Research Group on Cardiocirculatory Dynamism, Exploratory Research Center on Life and Living Systems, National Institute for Physiological Sciences, National Institutes of Natural Sciences, Okazaki, Japan, ${ }^{2}$ Department of Biomedical Science and Therapeutic, Faculty of Medicine and Health Sciences, Universiti Malaysia Sabah, Kota Kinabalu, Malaysia, ${ }^{3}$ Department of Physiological Sciences, School of Life Sciences, The Graduate University for Advanced Studies (SOKENDAl), Okazaki, Japan, ${ }^{4}$ Department of Translational Pharmaceutical Sciences, Graduate School of Pharmaceutical Sciences, Kyushu University, Fukuoka, Japan, ${ }^{5}$ Department of Pharmacology, Faculty of Pharmacy, Mahidol University, Bangkok, Thailand

\section{OPEN ACCESS}

Edited by:

Paulo Correia-de-Sá, Universidade do Porto, Portugal

Reviewed by: António Albino-Teixeira, University of Porto, Portugal

Wayne Rodney Giles,

University of Calgary, Canada

*Correspondence:

Motohiro Nishida

nishida@nips.ac.jp

tThese authors have contributed equally to this work.

Specialty section:

This article was submitted to Cardiovascular and Smooth Muscle

Pharmacology,

a section of the journal Frontiers in Pharmacology

Received: 22 January 2018 Accepted: 01 May 2018 Published: 22 May 2018

Citation:

Sunggip C, Shimoda K, Oda S, Tanaka T, Nishiyama $K$, Mangmool S, Nishimura A, Numaga-Tomita $T$ and Nishida $M$ (2018) TRPC5-eNOS Axis Negatively Regulates ATP-Induced

Cardiomyocyte Hypertrophy. Front. Pharmacol. 9:523. doi: 10.3389/fphar.2018.00523
Cardiac hypertrophy, induced by neurohumoral factors, including angiotensin II and endothelin-1, is a major predisposing factor for heart failure. These ligands can induce hypertrophic growth of neonatal rat cardiomyocytes (NRCMs) mainly through $\mathrm{Ca}^{2+}$. dependent calcineurin/nuclear factor of activated T cell (NFAT) signaling pathways activated by diacylglycerol-activated transient receptor potential canonical 3 and 6 (TRPC3/6) heteromultimer channels. Although extracellular nucleotide, adenosine $5^{\prime}$ triphosphate (ATP), is also known as most potent $\mathrm{Ca}^{2+}$-mobilizing ligand that acts on purinergic receptors, ATP never induces cardiomyocyte hypertrophy. Here we show that ATP-induced production of nitric oxide (NO) negatively regulates hypertrophic signaling mediated by TRPC3/6 channels in NRCMs. Pharmacological inhibition of NO synthase (NOS) potentiated ATP-induced increases in NFAT activity, protein synthesis, and transcriptional activity of brain natriuretic peptide. ATP significantly increased $\mathrm{NO}$ production and protein kinase G (PKG) activity compared to angiotensin II and endothelin-1. We found that ATP-induced $\mathrm{Ca}^{2+}$ signaling requires inositol 1,4,5trisphosphate $\left(\mathrm{IP}_{3}\right)$ receptor activation. Interestingly, inhibition of TRPC5, but not TRPC6 attenuated ATP-induced activation of $\mathrm{Ca}^{2+} / \mathrm{NFAT}-$ dependent signaling. As inhibition of TRPC5 attenuates ATP-stimulated NOS activation, these results suggest that NO-cGMP-PKG axis activated by $\mathrm{IP}_{3}$-mediated TRPC5 channels underlies negative regulation of TRPC3/6-dependent hypertrophic signaling induced by ATP stimulation.

Keywords: cardiac hypertrophy, TRPC cation channels, nitric oxide synthase, NFAT, adenosine triphosphate

\section{INTRODUCTION}

Myocardial hypertrophy is the major predisposing factor for heart failure, arrhythmia and sudden death (Levy et al., 1990). The initiation of hypertrophic stimuli for myocardial hypertrophy has been described through mechanical stress and neurohumoral mechanism that are associated with the release of factors such as angiotensin II (Ang II), endothelin-1 (ET-1) and norepinephrine 
(Dorn and Force, 2005; Heineke and Molkentin, 2006). Neurohumoral factors are known to stimulate $G$ protein-coupled receptor (GPCR), leading to activation of phospholipase $\mathrm{C}$ (PLC), which in turn generates diacylglycerol (DAG) and inositol 1,4,5-trisphosphate $\left(\mathrm{IP}_{3}\right)$ that are responsible for sustained increase in intracellular $\mathrm{Ca}^{2+}$ concentration $\left(\left[\mathrm{Ca}^{2+}\right]_{\mathrm{i}}\right)$ (Berridge et al., 2003). The sustained $\left[\mathrm{Ca}^{2+}\right]_{\mathrm{i}}$ increase induces pathological myocardial hypertrophy through activation of calcineurinnuclear factor of activated $\mathrm{T}$ cell (NFAT) signaling pathway (Molkentin et al., 1998; Berridge et al., 2003; Heineke and Molkentin, 2006).

Transient receptor potential canonical (TRPC) proteins are now accepted as molecular entities of receptor-activated cation channels (Molkentin et al., 1998; Clapham et al., 2001; NumagaTomita et al., 2017). There are seven mammalian TRPC (TRPC1-7) homologues, and TRPC2/3/6/7 subtypes are directly activated by DAG (Hofmann et al., 1999), while TRPC1/4/5 subtypes are activated by $\mathrm{IP}_{3}$-mediated $\mathrm{Ca}^{2+}$ release from $\mathrm{Ca}^{2+}$ store (Zhu et al., 1996). Studies have consistently shown that particularly DAG-activated TRPC3 and TRPC6 (TRPC3/6) channels function as an important mediator of GPCR-stimulated $\mathrm{Ca}^{2+}$ signaling pathway that may participate in pathological cardiac hypertrophy (Kuwahara et al., 2006; Nakayama et al., 2006; Onohara et al., 2006). Inhibition of TRPC3/6 channels have been reported to attenuate heart failure through suppressing myocardial hypertrophy and interstitial fibrosis (Kiyonaka et al., 2009; Kitajima et al., 2011, 2016; Numaga-Tomita et al., 2016).

Extracellular nucleotides, especially adenosine 5 'triphosphate (ATP), has long been recognized as an endogenous ligand to stimulate purinergic signaling (Erlinge and Burnstock, 2008). Evidence is accumulating that ATP and other purine/pyrimidine nucleotides play important roles in cardiovascular physiology and pathophysiology (Erlinge and Burnstock, 2008; Nishimura et al., 2017). Following emerging evidence on the role of ATP in cardiac homeostasis, blood circulatory ATP and its metabolites are now considered as reliable biomarkers for cardiac protection (Yeung, 2013; Zimmermann, 2016). ATP exerts its action in cardiomyocytes mostly through GPCR subtypes called P2Y purinergic receptors (Dubyak, 1991; Zimmermann, 2016). As one of the nucleotides released during cell stress, ATP is known to activate $\mathrm{Ca}^{2+}$ signaling pathway to initiate various biological processes. Although ATP activates $\mathrm{G}_{q^{-}}$PLC-dependent $\mathrm{Ca}^{2+}$ signaling pathway in cardiac cells (Nishida et al., 2011), it has been long obscure why ATP never induces cardiomyocyte hypertrophy (Post et al., 1996).

Paracrine modulation of cardiac excitation-contraction coupling (ECC) has recently become a topic of intense interest. Resident heart endothelial cells are well-known physiological paracrine modulators of cardiac myocyte ECC mainly via nitric oxide (NO) and ATP (Mayourian et al., 2018). We previously reported that ATP has potency to induce NO production leading to heterologous downregulation of Ang II type1 receptors (AT1Rs) and senescence in cardiac cells (Nishida et al., 2011). As NO-mediated protein kinase G (PKG) activation through guanylate cyclase-dependent cyclic guanosine $3^{\prime}, 5^{\prime}$-monophosphate (cGMP) production attenuates
TRPC3/6 channel activity and calcineurin-NFAT signaling (Fiedler et al., 2002; Nishida et al., 2010), we hypothesize that $\mathrm{NO} / \mathrm{cGMP} / \mathrm{PKG}$-mediated suppression of TRPC3/6 channel activity underlies negative regulation of hypertrophic growth of cardiomyocytes induced by ATP stimulation. In this study, we demonstrate that ATP induces $\mathrm{IP}_{3}$-dependent $\mathrm{Ca}^{2+}$ signaling and NO production in neonatal rat cardiomyocytes (NRCMs), as well as functional coupling between $\mathrm{IP}_{3}$-responsive TRPC5 channel and endothelial NOS (eNOS) contributes to negative regulation of hypertrophic signaling induced by ATP stimulation.

\section{MATERIALS AND METHODS}

\section{Materials and Cell Cultures}

4-\{[3', $4^{\prime}$-(methylenedioxy)benzyl $]$ amino $\}$-6-methoxyquinazoline (MQ), KT5823, ionomycin and xestospongin C were purchased from Calbiochem. 8-bromo- cyclic guanosine $3^{\prime}, 5^{\prime}$-monophosphate (8-Br-cGMP), S-nitroso- $N$-acetyl-DLpenicillamine (SNAP), 1-oleoyl-2-acetyl-sn-glycerol (OAG), ET-1, U73122, 8-Cyclopentyl-1,3-dipropylxanthine (DPCPX) and 2-Aminoethyl diphenylborinate (2-APB) were from Sigma. Ang II was from Peptide Lab. AR-C 118925XX, UTP $\gamma$ S trisodium salt, SCH58261 and MRS1754 were from Tocris Bioscience. Fura 2-AM and $\mathrm{N} \omega$-nitro-L-arginine methyl ester hydrochloride (L-NAME) were from Dojindo. Diaminofluorescein-2 diacetate (DAF-2 DA) was from Molecular Probes. Dulbecco's modified Eagle's medium (DMEM) was from Wako. Anti-TRPC5, anti-TRPC6 antibodies were from Alomone. Anti-phosphoeNOS (Ser1177), horseradish peroxidase (HRP)-conjugated anti-rabbit IgG and HRP-conjugated anti-mouse IgG were from Santa Cruz Biotechnology. Anti-eNOS antibody was from BD Biosciences. Plasmids encoding NFAT promoter-dependent luciferase and brain natriuretic peptide (BNP) promoterdependent luciferase, and dual luciferase reporter assay system were from Promega. Collagenase II was from Worthington. Stealth siRNAs for rat TRPC5 and TRPC6, Lipofectamine 2000, and Lipofectamine RNAiMAX reagent were purchased from Invitrogen.

All protocols using rat pups were reviewed and approved by the ethic committees at National Institutes of Natural Sciences or the Animal Care and Use Committee, Kyushu University, and were performed according to the institutional guidelines concerning the care and handling of experimental animals. NRCMs were prepared from the ventricles of 1-2-day-old SD rats as described (Nishida et al., 2010). The minced left ventricular tissue was pre-digested in $0.05 \%$ trypsin-EDTA (Gibco) over night at $4^{\circ} \mathrm{C}$ and then digested in $1 \mathrm{mg} / \mathrm{ml}$ collagenase type 2 (Worthington) in PBS for $30 \mathrm{~min}$ at $37^{\circ} \mathrm{C}$. The dissociated cells were plated in a $10-\mathrm{cm}$ culture dish and incubated at $37^{\circ} \mathrm{C}$ in a humidified atmosphere $\left(5 \% \mathrm{CO}_{2}, 95 \%\right.$ air $)$ for $1 \mathrm{~h}$ in DMEM containing $10 \%$ FBS and $1 \%$ penicillin and streptomycin. Floating cells were collected and plated into gelatin-coated culture dishes at a density of around $1.5 \times 10^{5}$ cells $/ \mathrm{cm}^{2}$. After $24 \mathrm{~h}$, the culture medium was changed to serum-free DMEM. We confirmed that $>90 \%$ attached cells were actinin-positive by immunostaining. For TRPC knockdown, NRCMs were transfected with each 
siRNA (50 nM) using Lipofectamine RNAiMAX for $72 \mathrm{~h}$ (Nishida et al., 2010; Kitajima et al., 2016).

\section{Measurement of Intracellular $\mathrm{Ca}^{2+}$ Increases and NO Production}

Measurement of intracellular $\mathrm{Ca}^{2+}$ increases was performed with Fura 2-AM as previously described (Nishida et al., 2010; Kitajima et al., 2016). After aspirating the culture medium from the dishes and washing the cells with DMEM, freshly prepared Fura 2-AM $(1 \mu \mathrm{M})$ diluted in DMEM was added to the dishes and incubated for $30 \mathrm{~min}$ at $37^{\circ} \mathrm{C}$. As to the measurement of NO production, NRCMs were incubated with DAF-2 DA $(10 \mu \mathrm{M})$ for $20 \mathrm{~min}$. The dye solution was then replaced with HEPES-buffered saline solution (HBSS) containing $140 \mathrm{mM}$ $\mathrm{NaCl}, 5.6 \mathrm{mM} \mathrm{KCl}, 10 \mathrm{mM}$ glucose, $10 \mathrm{mM}$ HEPES ( $\mathrm{pH}$ 7.4), $1 \mathrm{mM} \mathrm{MgCl}_{2}$ and $2 \mathrm{mM} \mathrm{CaCl}$. $\mathrm{CaCl}_{2}$ was omitted in $\mathrm{Ca}^{2+}$. free HBSS. Fura-2 was excited by $340 \mathrm{~nm}$ and $380 \mathrm{~mm}$ UV wavelength and fluorescence images at the emission wavelength of $\geq 510 \mathrm{~nm}$ were recorded and ratiometrically analyzed using a video image analysis system (Aquacosmos, Hamamatsu). DAF-2 DA was excited by $470 \pm 20 \mathrm{~nm}$, and the fluorescence images at the wavelength of $525 \pm 20 \mathrm{~nm}$ were acquired using fluorescence microscopy (BZ-X710, Keyence). The fluorescence intensity of the digital images were analyzed using Image J software. Fold increases in fluorescence were calculated by subtracting fluorescence intensity before stimulation from that after stimulation, which was subsequently divided by that of no-stimulation.

\section{Reporter Activity}

Measurement of NFAT-dependent luciferase activity and BNP promoter-dependent luciferase activity was performed as described previously (Nishida et al., 2010, 2011).

\section{Western Blot Analysis}

NRCMs $\left(1 \times 10^{6}\right.$ cells $)$ plated on 6-well dishes were directly harvested with $2 \times$ SDS sample buffer $(200 \mu l)$. After centrifugation, supernatants $(20-40 \mu \mathrm{l})$ were fractionated by $8 \%$ SDS-polyacrylamide gel and then transferred onto polyvinylidene difluoride membrane. The expression and phosphorylation of endogenous TRPC proteins were detected by anti-TRPC6 (dilution rate, 1:1000) and anti-TRPC5 (1:1000) antibodies. We visualized the reactive bands using Western Lightning Plus ECL (PerkinElmer). The optical density of the film was scanned and measured with Scion Image software.

\section{Hypertrophic Responses of Cardiomyocytes}

Measurement of hypertrophic responses was performed by measuring the transcriptional activation of BNP gene as described previously (Onohara et al., 2006). Protein synthesis was measured by $\left[{ }^{3} \mathrm{H}\right]$ leucine incorporation (Onohara et al., 2006; Nishida et al., 2010). After cells were stimulated with agonists for $2 \mathrm{~h},\left[{ }^{3} \mathrm{H}\right]$ leucine $(1 \mu \mathrm{Ci} / \mathrm{ml})$ was added to the culture medium and further incubated for $4 \mathrm{~h}$. The incorporated $\left[{ }^{3} \mathrm{H}\right]$ leucine was measured using a liquid scintillation counter.

\section{Statistical Analysis}

Results are presented as the mean \pm SEM. Statistical comparisons were made using Student's $t$-test (for two groups) or analysis of variance followed by Tukey's post hoc test (for multiple groups). Values of $P<0.05$ were considered significant. We made utmost effort to minimize the replicates of animal experiments according to the ethical guideline of 3R (Replacement, Reduction, Refinement).

\section{RESULTS}

\section{ATP Increases $\left[\mathrm{Ca}^{2+}\right]_{\mathrm{i}}$ and NFAT Activity but Fails to Induce Hypertrophic Growth in NRCMs}

We first investigated the effect of ATP on $\mathrm{Ca}^{2+}$-NFAT signaling in NRCMs, as well as known hypertrophy-inducible ligands,

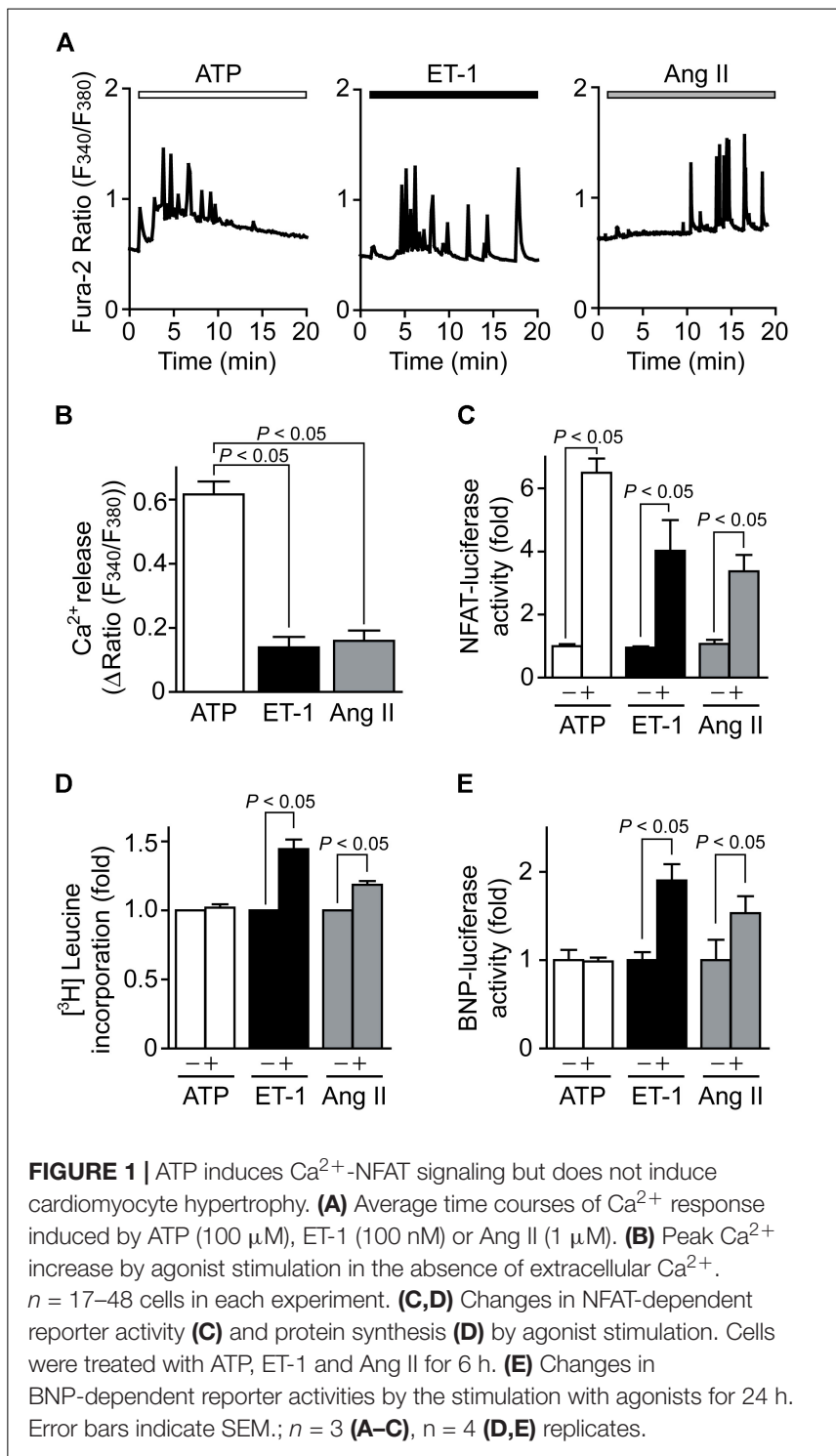


ET-1 (Nishida et al., 2010) and Ang II (Onohara et al., 2006). ATP showed repetitive transient $\left[\mathrm{Ca}^{2+}\right]_{i}$ increase events that are superimposed on a substantial maintained increase in $\left[\mathrm{Ca}^{2+}\right]_{\mathrm{i}}$, while ET-1 and Ang II induced smaller but sustained oscillatory increases in $\left[\mathrm{Ca}^{2+}\right]_{\mathrm{i}}$ (Figures 1A,B). ATP increased NFAT-dependent transcriptional activity more potently than ET-1 and Ang II (Figure 1C). In contrast, despite increasing NFAT activity, ATP never increased hypertrophic responses, including protein synthesis determined by $\left[{ }^{3} \mathrm{H}\right]$ leucine incorporation and transcriptional activation of BNP (Figures 1D,E). These results indicate that ATP-induced increases in $\left[\mathrm{Ca}^{2+}\right]_{\mathrm{i}}$ and NFAT activity are not sufficient to induce hypertrophic responses in NRCMs.

\section{Inhibition of NO Synthesis Potentiates ATP-Induced NFAT Activation and Triggers Hypertrophic Response}

We next examined which signal pathway(s) induced by ATP stimulation negatively regulates hypertrophic growth of
NRCMs. Previously we reported that mechanical stretch on NRCMs induces ATP release, which leads to NO production through $\mathrm{P}_{2} \mathrm{Y}_{2}$ receptor stimulation (Nishida et al., 2011). As NO has potent anti-hypertrophic effect by activating cGMP/PKG-dependent pathway in heart (Lefroy et al., 1993), we investigated the involvement of $\mathrm{NO}$ in ATP-induced NFAT activation and hypertrophic responses. As shown in Figures 2A,B, ATP stimulation induced a powerful transient increase in NFAT activity compared to ET-1 stimulation in NRCMs. Treatment with L-NAME $(100 \mu \mathrm{M})$, an inhibitor of NOS, resulted in significant enhancement of ATP-induced sustained NFAT activation to the same extent of that by ET1 stimulation, while L-NAME had no impact on ET-1-induced NFAT activation. L-NAME also enhanced BNP transcriptional activation in response to ATP stimulation (Figure 2C). The enhanced BNP activity was canceled by the treatment with MQ $(10 \mu \mathrm{M})$, a phosphodiesterase (PDE) 5 selective inhibitor, suggesting the involvement of cGMP-dependent pathway. ATP produced a small transient increase in $\left[\mathrm{Ca}^{2+}\right]_{i}$ in the absence of extracellular $\mathrm{Ca}^{2+}$ (Figures 2D,E, a), which was
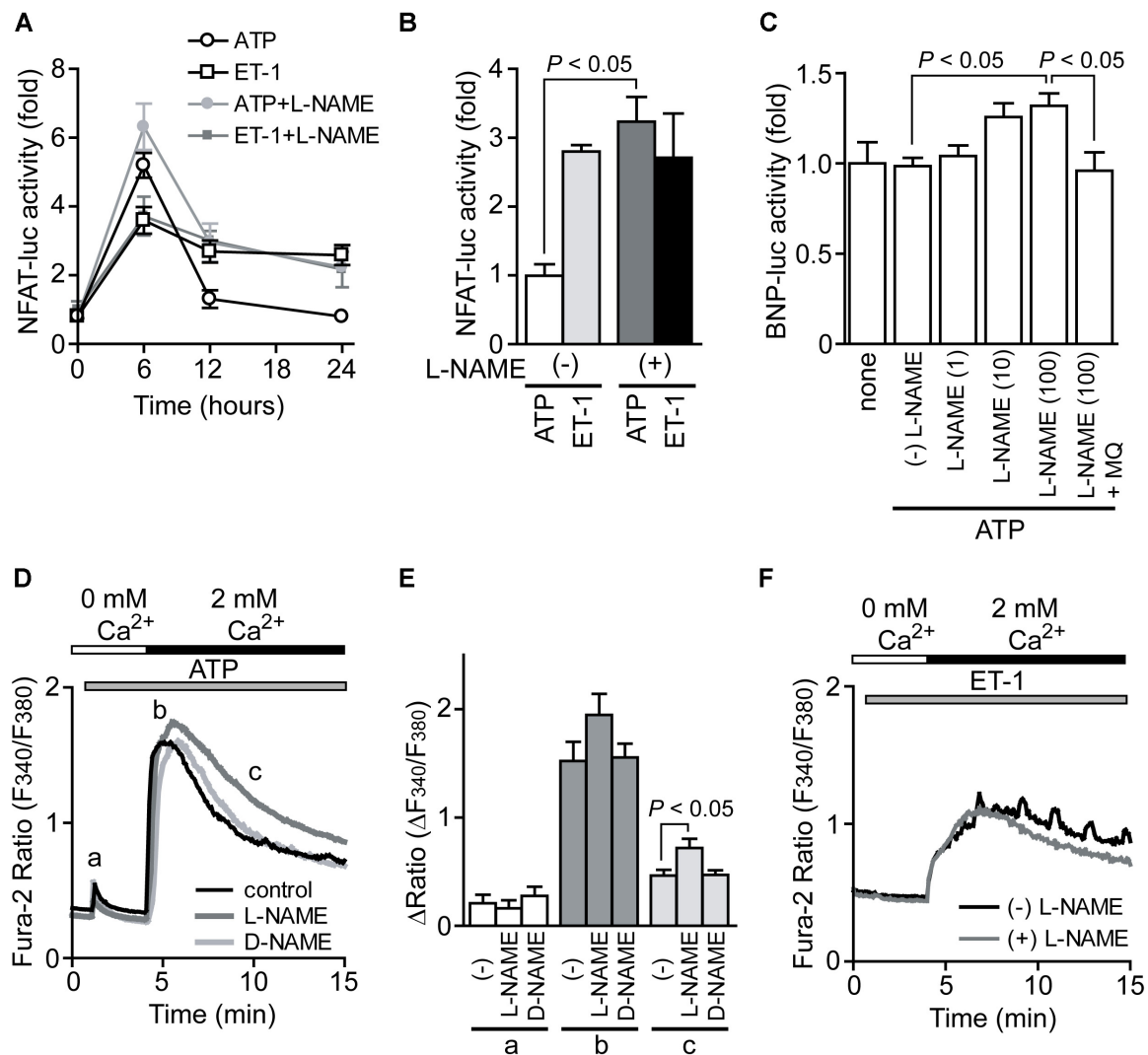

FIGURE 2 | Potentiation of ATP-induced NFAT activation by inhibition of NO synthesis. (A) Time courses of NFAT activation by agonist stimulation. Cells were treated with L-NAME $(100 \mu \mathrm{M}) 20$ min prior to stimulation with ATP $(100 \mu \mathrm{M})$ or ET-1 (100 nM). (B) Effects of L-NAME on the increase in NFAT-luciferase (luc) activities by the stimulation with ATP or ET-1 for $24 \mathrm{~h}$. (C) Effects of L-NAME on ATP-induced changes in BNP-luc activities. Cells were treated with indicated concentration ( $\mu$ M) of L-NAME and MQ $(10 \mu \mathrm{M}) 20$ min prior to ATP stimulation for $24 \mathrm{~h}$. (D) Average time courses of ATP-induced $\mathrm{Ca}^{2+}$ responses. Ca ${ }^{2+}$ release was first evoked in $\mathrm{Ca}^{2+}$-free solution, and $\mathrm{Ca}^{2+}$ entry-mediated $\mathrm{Ca}^{2+}$ responses were induced by the addition of $2 \mathrm{mM} \mathrm{Ca}^{2+}$. Cells were treated with L-NAME and D-NAME $(100 \mu \mathrm{M}) 30$ min prior to ATP stimulation. (E) Peak ATP-induced increases in $\left[\mathrm{Ca}^{2+}\right]_{\mathrm{i}}$ in $\mathrm{Ca}^{2+}$-free solution (a) and after the addition of $\mathrm{Ca}^{2+}(\mathrm{b})$, and [Ca $\left.{ }^{2+}\right]_{\mathrm{i}}$ increases sustained 6 min after addition of $\mathrm{Ca}^{2+}$ (C). (F) Effects of L-NAME on ET-1-induced Ca ${ }^{2+}$ responses. $n=22-61$ cells. Error bars indicate SEM.; $n=8$ (A,B) $n=4$ (C), $n=3$ (D-F) replicates. 
mainly derived from intracellular $\mathrm{IP}_{3}$-responsive $\mathrm{Ca}^{2+}$ store. Replenishing extracellular $\mathrm{Ca}^{2+}$ led to sustained increases in $\left[\mathrm{Ca}^{2+}\right]_{\mathrm{i}}$, which was derived from $\mathrm{Ca}^{2+}$ influx probably through store-operated $\mathrm{Ca}^{2+}$ channels (Figures 2D,E, b and c). Treatment with L-NAME, but not D-NAME (inactive analog of L-NAME), significantly suppressed sustained $\left[\mathrm{Ca}^{2+}\right]_{i}$ increase (Figures 2D,E, c). In contrast, although ET-1 stimulation also induced sustained $\left[\mathrm{Ca}^{2+}\right]_{\mathrm{i}}$ increase, L-NAME failed to suppress the ET-1-induced sustained $\left[\mathrm{Ca}^{2+}\right]_{\mathrm{i}}$ increase in NRCMs (Figure 2F). These results suggest that ATP induces NO production in NRCMs and negatively regulates $\mathrm{Ca}^{2+} /$ NFATdependent hypertrophic signaling.

\section{ATP Activates NO-Dependent Signaling in NRCMs}

We next examined whether ATP actually induces activation of $\mathrm{NO}$-dependent signaling in NRCMs. Compared to stimulation of NRCMs with ET-1 and Ang II, stimulation with ATP significantly increased fluorescence intensity of DAF-2, an NO-sensitive dye (Figures 3A,B). Heart expresses all three isoforms of NOS (Balligand and Cannon, 1997), and the activity of the constitutively expressed isoform eNOS is predominantly regulated by its phosphorylation at Ser1177 (Michell et al., 1999). ATP actually increased eNOS phosphorylation at Ser1177

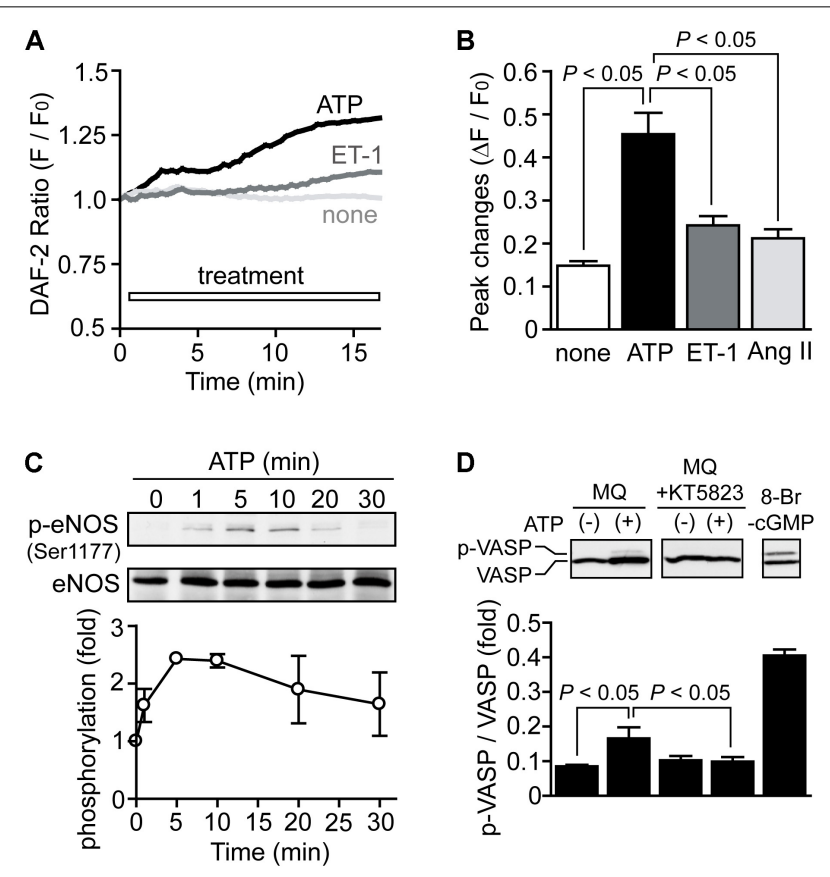

FIGURE 3 | Activation of NO-dependent signaling pathway by ATP. (A,B) Average time courses of changes $(\mathbf{A})$ and peak increases $(\mathbf{B})$ in intracellular NO concentration by agonist stimulation. $n=7-22$ cells in each experiment. (C) Time courses of eNOS phosphorylation induced by ATP.

(D) PKG-dependent VASP phosphorylation induced by ATP. Cells were treated with $\mathrm{MQ}(10 \mu \mathrm{M})$ and $\mathrm{KT} 5823(1 \mu \mathrm{M}) 60$ min prior to ATP stimulation for $15 \mathrm{~min}$. Cells were also stimulated with 8-Br-cGMP $(30 \mu \mathrm{M})$ for 15 min as a positive control. Error bars indicate SEM.; $n=3$ replicates.
(Figure 3C). We further measured the phosphorylation of vasodilator-stimulated phosphoprotein (VASP), a substrate of PKG (Eigenthaler et al., 1992). Stimulation of NRCMs with ATP under PDE5 inhibition slightly but significantly increased phosphorylation level of VASP protein, and this phosphorylation was completely abolished by KT5823 (1 $\mu \mathrm{M})$, a PKG inhibitor (Figure 3D). These results indicate that ATP induces activation of NO-cGMP-PKG pathway in NRCMs.

\section{TRPC6 Is Not Involved in ATP-Induced $\mathrm{Ca}^{2+}$ Responses}

We previously reported that TRPC6, rather than TRPC3, predominantly mediates mechanical stretch-induced global $\left[\mathrm{Ca}^{2+}\right]_{\mathrm{i}}$ increase in NRCMs (Nishida et al., 2010; Kitajima et al., 2016). We also reported that ATP released from NRCMs
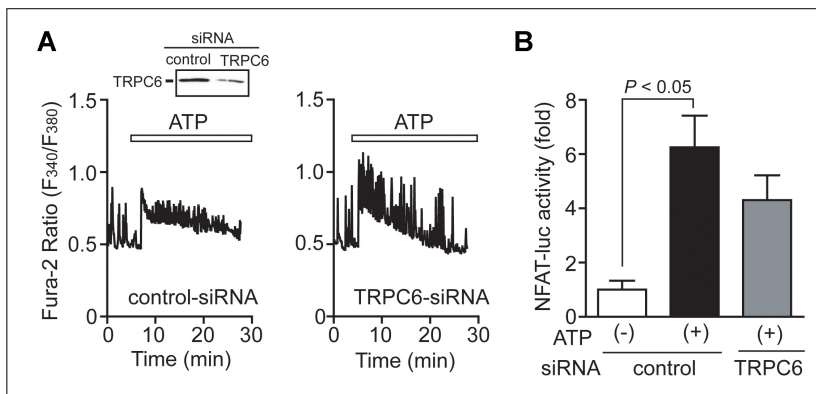

C
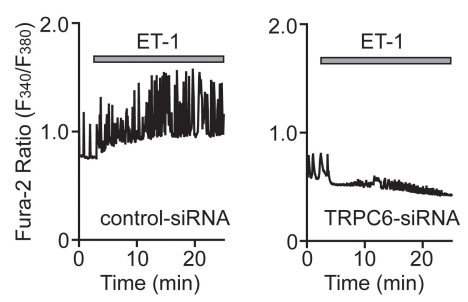

D

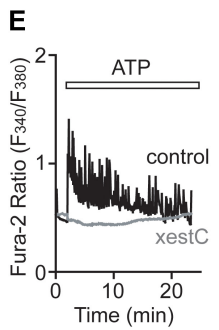

$\mathbf{F}$
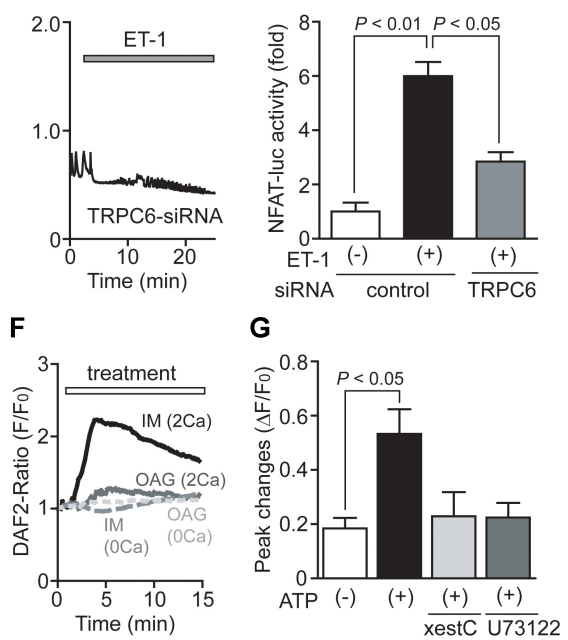

FIGURE 4 | TRPC6 is not involved in ATP-induced $\mathrm{Ca}^{2+}$ responses. (A,C) Effects of TRPC6-siRNA on $\mathrm{Ca}^{2+}$ responses induced by ATP (A) or ET-1 (C). $n=19-32$ cells in each experiment. (B,D) Effects of TRPC6-siRNA on the increases in NFAT-luciferase activity induced by ATP (B) or ET-1 (D). Three days after transfection with TRPC6-siRNA (1786) or control-siRNA, cells were treated with ATP $(100 \mu \mathrm{M})$ or ET-1 $(100 \mathrm{nM})$ for $6 \mathrm{~h}$. (E) Effects of xestospongin $\mathrm{C}$ (xestC) on ATP-induced $\mathrm{Ca}^{2+}$ responses. $n=16-31$ cells in each experiment. (F) Time courses of changes in intracellular NO concentration induced by ionomycin $(\mathrm{IM} ; 1 \mu \mathrm{M})$ or $\mathrm{OAG}(30 \mu \mathrm{M})$ in the presence or absence of extracellular $\mathrm{Ca}^{2+} . n=12-38$ cells in each experiment. (G) Effects of xestC and U73122 on the ATP-induced NO production. Cells were treated with xestC $(20 \mu \mathrm{M})$ or U73122 $(1 \mu \mathrm{M}) 40 \mathrm{~min}$ prior to ATP stimulation. Error bars indicate SEM.; $n=3$ (A,C,E-G), $n=4$ $\mathbf{B}, \mathbf{D})$ replicates. 
mediates mechanical stretch-induced $\mathrm{G}_{12 / 13}$ protein signaling in an autocrine/paracrine manner (Nishida et al., 2008). Therefore, we next investigated whether TRPC6 participates in ATP-induced $\mathrm{Ca}^{2+}$ signaling in NRCMs. Interestingly, knockdown of TRPC6 failed to attenuate ATP-induced increases in $\left[\mathrm{Ca}^{2+}\right]_{i}$ and NFAT activity in NRCMs (Figures 4A,B), while significantly reducing ET-1-induced increases in $\left[\mathrm{Ca}^{2+}\right]_{\mathrm{i}}$ and NFAT activity (Figures 4C,D). The ATP-induced $\mathrm{Ca}^{2+}$ response was completely suppressed by the treatment with xestospongin $\mathrm{C}(20 \mu \mathrm{M})$, an $\mathrm{IP}_{3}$ receptor $\left(\mathrm{IP}_{3} \mathrm{R}\right)$ blocker (Figure $\left.4 \mathrm{E}\right)$. As eNOS activity is predominantly regulated by the increase in $\left[\mathrm{Ca}^{2+}\right]_{\mathrm{i}}$ as well as its phosphorylation, we further investigated whether $\mathrm{IP}_{3}$ dependent store-operated $\mathrm{Ca}^{2+}$ influx signaling mediates eNOS activation by ATP stimulation. Store-operated $\mathrm{Ca}^{2+}$ influx was evoked by the treatment with ionomycin (1 $\mu \mathrm{M})$, a $\mathrm{Ca}^{2+}$ ionophore (Nishida et al., 2003). Treatment with ionomycin but not OAG $(30 \mu \mathrm{M})$, a membrane-permeable DAG analog,

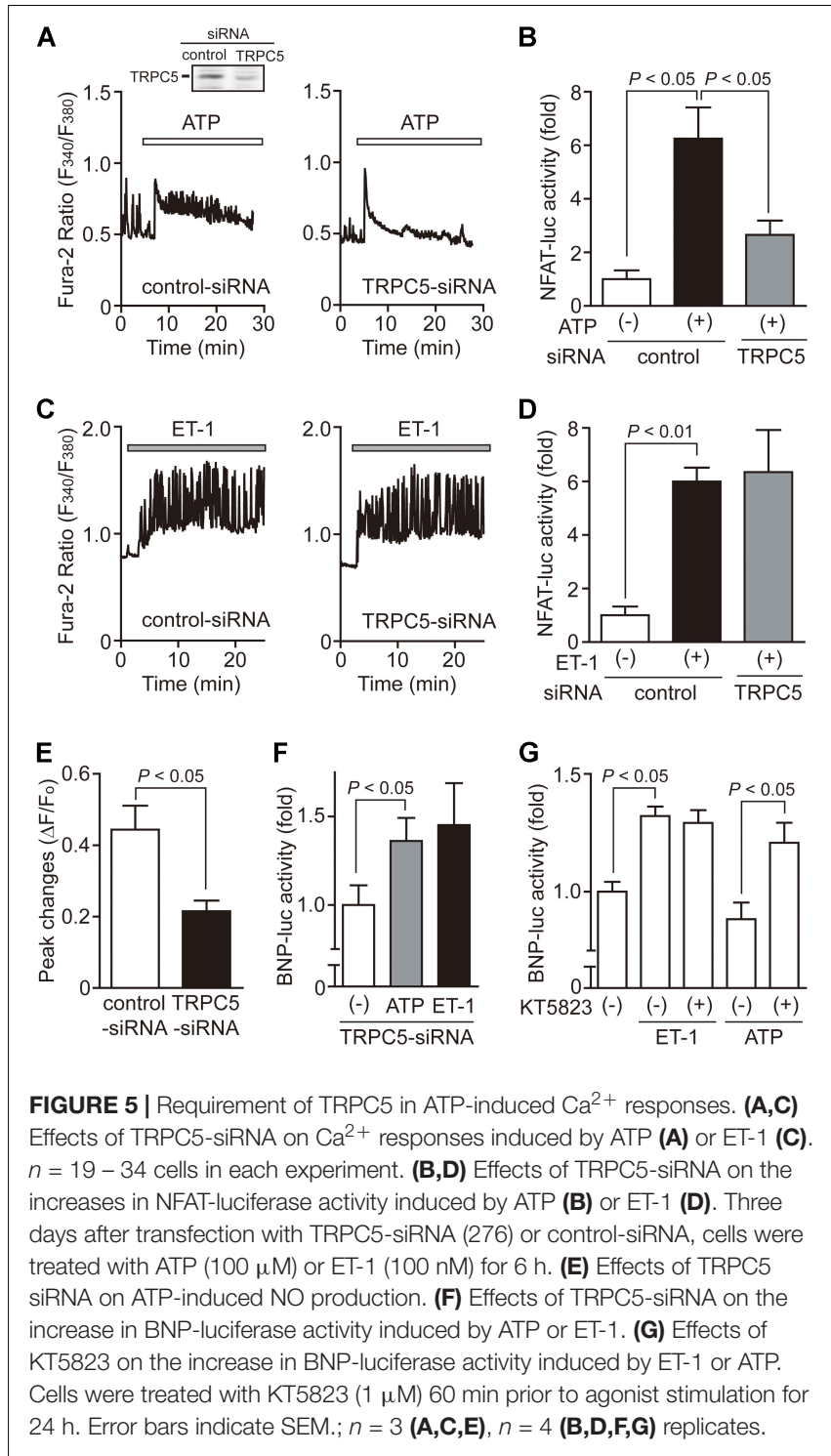

increased intracellular $\mathrm{NO}$ concentration in the presence of extracellular $\mathrm{Ca}^{2+}$ (Figure 4F). The ionomycin-induced NO production was completely diminished in the absence of extracellular $\mathrm{Ca}^{2+}$, indicating that store-operated $\mathrm{Ca}^{2+}$ influx is required for ATP-induced NO production in NRCMs. Additionally, inhibition of $\mathrm{IP}_{3} \mathrm{R}$ or PLC suppressed ATP-induced NO production in NRCMs (Figure 4G). These results suggest that ATP-induced $\mathrm{Ca}^{2+} / \mathrm{NFAT}$ signaling and $\mathrm{NO}$ production are not mediated by DAG-activated channels, including TRPC6.

\section{IP 3 -Responsive TRPC5 Channel Partially Participates in ATP-Induced $\mathrm{Ca}^{2+}$ Signaling in NRCMs}

TRPC5 has been shown to be upregulated in human failing heart, although its physiological role is still not fully understood (Bush et al., 2006). TRPC5 is one of the $\mathrm{IP}_{3}$-responsive TRPC channels, and reported to form stable protein complex with eNOS to amplify NO signaling in endothelial cells (Yoshida et al., 2006). We thus investigated whether TRPC5
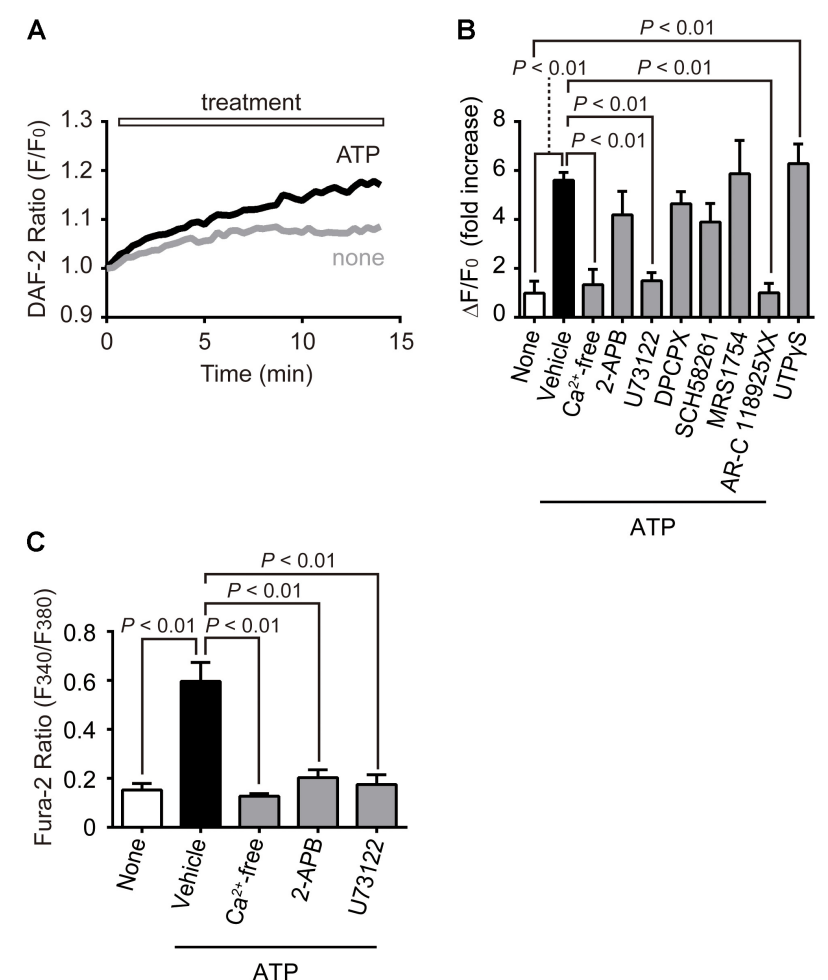

FIGURE $6 \mid \mathrm{P} 2 \mathrm{Y}_{2} \mathrm{R}-\mathrm{PLC}-\mathrm{Ca}^{2+}$ influx axis mediates ATP-induced NO production in NRCMs. (A) Time-courses of relative changes of DAF fluorescence intensity $\left(F / F_{0}\right)$ in the presence or absence of ATP $(100 \mu \mathrm{M})$. (B) Effects of inhibitors on ATP-induced NO production. NRCMs were pretreated with 2-APB (10 $\mu \mathrm{M}, n=4$ replicates), U73122 ( $1 \mu \mathrm{M}, n=4)$, $\operatorname{DPCPX}(1 \mu \mathrm{M}, n=3)$, SCH58261 (0.5 $\mu \mathrm{M}, n=3), \operatorname{MRS} 1754(0.5 \mu \mathrm{M}, n=3)$ and AR-C118925XX (10 $\mu \mathrm{M}, n=3) 20$ min before ATP stimulation. NRCMs were stimulated with ATP in the absence of extracellular $\mathrm{Ca}^{2+}\left(\mathrm{Ca}^{2+}\right.$-free, $n=4)$. $P 2 Y_{2 / 4} R s$ of NRCMs were selectively stimulated with UTP $\gamma S(1 \mu \mathrm{M}$, $n=3)$. (C) Effects of inhibitors on ATP-induced $\left[\mathrm{Ca}^{2+}\right]_{\mathrm{i}}$ increases $(n=3$ replicates). Error bars indicate SEM. 
participates in ATP-induced $\mathrm{Ca}^{2+}$ signaling and NO production in NRCMs. Surprisingly, knockdown of TRPC5 significantly suppressed the ATP-induced sustained increase in $\left[\mathrm{Ca}^{2+}\right]_{i}$, but not transient $\left[\mathrm{Ca}^{2+}\right]_{\mathrm{i}}$ increase (Figure 5A). TRPC5 knockdown also attenuated the NFAT activity in ATP-stimulated NRCMs (Figure 5B). In contrast, the ET-1-induced increases in $\left[\mathrm{Ca}^{2+}\right]_{\mathrm{i}}$ and NFAT activity were not reduced by TRPC5 knockdown (Figures 5C,D). We also found that TRPC5 knockdown markedly reduced ATP-induced NO production (Figure 5E), and increased ATP-induced BNP transcriptional activity at a rate similar to ET-1 stimulation (Figure $5 \mathrm{~F}$ ). The induction of hypertrophic response by ATP stimulation in TRPC5 knockdown NRCMs were mimicked by the treatment with KT5823 (Figure 5G). These results suggest that TRPC5 acts as negative regulator of hypertrophic signaling in NRCMs through eNOS-mediated activation of NO/cGMP/PKG signaling.

\section{P2Y $_{2}$ R-PLC-IP $3-\mathrm{Ca}^{2+}$ Influx Axis Mediates ATP-Induced NO Production in NRCMs}

We finally examined which purinergic receptor subtype(s) mediates ATP-induced NO production in NRCMs. As expected, the ATP-induced NO production was significantly suppressed by pharmacological inhibition of PLC by U73122 (1 $\mu \mathrm{M})$ or $\mathrm{P}_{2} \mathrm{Y}_{2} \mathrm{R}$ by AR-C 118925XX $(10 \mu \mathrm{M})$ (Figures 6A,B). Stimulation with $\mathrm{UTP} \gamma \mathrm{S}$, a $\mathrm{P}_{2} \mathrm{Y}_{2 / 4} \mathrm{R}$-selective ligand, also increased NO production. In addition, U73122 suppressed the ATP-induced $\mathrm{Ca}^{2+}$ response (Figure 6C). As AR-C 118925XX has yellow-colored self-fluorescence that entirely overlaps F340 intensity of Fura-2, we could not measure the exact ratiometric changes of fura- 2 induced by ATP stimulation in the presence of AR-C118925XX. However, we confirmed that AR-C 118925XX completely suppressed the ATP-induced increase in F340 intensity of Fura-2 (data not shown). These results strongly suggest that $\mathrm{P}_{2} \mathrm{Y}_{2} \mathrm{R}-\mathrm{PLC}$ axis predominantly mediates ATP-induced $\mathrm{Ca}^{2+}$ response and $\mathrm{NO}$ production in NRCMs.

Extracellular ATP is rapidly converted into ADP, AMP and adenosine by membrane-bound ectonucleotidases (Nishimura et al., 2017). Adenosine receptors are reported to participate in the regulation of $\mathrm{NO}$ in the heart and many effects of adenosine are mediated via NO-cGMP pathways (Sterin-Borda et al., 2002). However, treatment of NRCMs with DPCPX (1 $\mu \mathrm{M}$, $\mathrm{A}_{1} \mathrm{R}$-selective antagonist), SCH58261 (0.5 $\mu \mathrm{M}, \mathrm{A}_{2 \mathrm{~A}} \mathrm{R}$-selective antagonist), and MRS1754 (0.5 $\mu \mathrm{M}, \mathrm{A}_{2 \mathrm{~B}} \mathrm{R}$-selective antagonist) did not significantly suppress ATP-induced NO production (Figure 6). Therefore, adenosine receptors may hardly contribute to ATP-induced anti-hypertrophic NO signaling in NRCMs.

As the removal of extracellular $\mathrm{Ca}^{2+}$ also suppressed ATPinduced $\mathrm{Ca}^{2+}$ response and NO production, some $\mathrm{Ca}^{2+}$ influx pathway(s) may be activated by ATP stimulation. However, the context of store-operated $\mathrm{Ca}^{2+}$ channels (SOCs) are hardly developed in matured cardiomyocytes, and the treatment with 2 -APB $(10 \mu \mathrm{M})$, an inhibitor of SOCs, suppressed $\mathrm{Ca}^{2+}$ response but not NO production induced by ATP stimulation. Thus, $\mathrm{IP}_{3}$-dependent TRPC5-mediated $\mathrm{Ca}^{2+}$ influx pathway, but not other $\mathrm{Ca}^{2+}$ release-activated $\mathrm{Ca}^{2+}$ influx pathway, is involved in ATP-induced $\mathrm{Ca}^{2+}$-dependent $\mathrm{NO}$ production in NRCMs.

\section{DISCUSSION}

Although the physiological importance of NO-dependent signaling in heart has been long discussed, the major origin of NO was generally thought to be endothelial cells because of poor expression levels of NOS enzymes in NRCMs. However, local activation of NO signaling in cardiomyocyte induced by sex

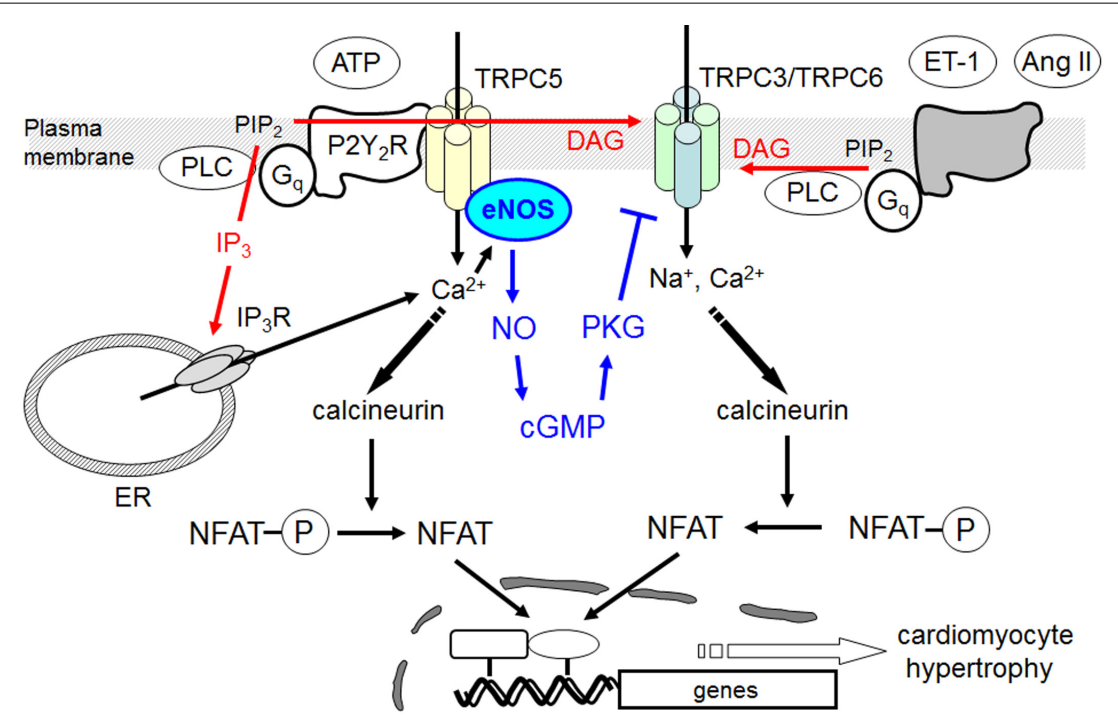

FIGURE 7 | Negative regulation of hypertrophic responses by TRPC5-eNOS signaling axis in cardiomyocyte. TRPC5 functionally couples with eNOS, and activation of TRPC5-mediated NO signaling negatively regulates hypertrophic responses by suppressing TRPC3/C6-mediated Na ${ }^{+} / \mathrm{Ca}^{2+}$ influx and sustained $\mathrm{Ca}{ }^{2}+/ \mathrm{NFAT}$ activation in ATP-stimulated cardiomyocytes. 
hormone receptor stimulation has been also attracting attention as a negative regulatory mechanism of cardiac arrhythmia (Bai et al., 2005). The role of $\mathrm{Ca}^{2+} / \mathrm{NFAT}$ signaling in cardiac hypertrophy is well established, and local $\mathrm{Ca}^{2+}$ influx through TRPC3/6 channels may be a putative mechanism underlying activation of calcineurin-NFAT signaling pathway in rodent myocardium. We demonstrated that ATP-induced increases in $\left[\mathrm{Ca}^{2+}\right]_{\mathrm{i}}$ and NFAT activity are not sufficient to induce hypertrophic responses in NRCMs. Previous studies revealed that sustained $\mathrm{Ca}^{2+}$ oscillation is more efficient in activating NFAT-dependent hypertrophic gene expression than transient $\mathrm{Ca}^{2+}$ rise induced by hypertrophy-inducible ligands and mechanical stretch (Dolmetsch et al., 1998; Colella et al., 2008). We revealed that ATP stimulation induced a powerful transient $\left[\mathrm{Ca}^{2+}\right]_{\mathrm{i}}$ increase compared to other hypertrophyinducible ligands, Ang II and ET-1. Similarly, although NFAT transcriptional activity was increased transiently, the actual hypertrophic response should require maintained presence of NFAT, which is not achievable with ATP stimulation. A large body of evidence indicated that NO production is likely to represent a protective mechanism against cardiac hypertrophy (Balligand and Cannon, 1997). We found that ATP can induce NO production in NRCMs. Inhibition of NO production by L-NAME indeed resulted in potentiation of ATP-induced sustained NFAT activity and induction of hypertrophic response. ATP acts on both P2X channels and $\mathrm{P} 2 \mathrm{Y}$ receptors, and $\mathrm{P} 2 \mathrm{Y}_{2}$ receptor is predominantly expressed in NRCMs (Nishida et al., 2008, 2011). We previously reported that $\mathrm{P}_{2} \mathrm{Y}_{2}$ receptor stimulation induces $\mathrm{NO}$ signaling in rat cardiac fibroblasts and NRCMs through induction of inducible NOS (iNOS) (Nishida et al., 2011). In this study, we newly found that TRPC5 participates in ATP-stimulated NO signaling in NRCMs. While it is still unclear whether TRPC5 also participates in ATP-induced iNOS induction of NRCMs, our results clearly suggest that TRPC5-mediated NO signaling contributes to negative regulation of sustained NFAT signaling and hypertrophic responses induced by ATP in NRCMs (Figure 7).

Although TRPC5 expression is upregulated in pathologic hypertrophied human hearts (Bush et al., 2006), its physiological meaning has been still obscure. We demonstrated that TRPC5mediated $\mathrm{Ca}^{2+}$ influx negatively regulates ATP-induced hypertrophic response of NRCMs through activation of NO signaling. Indeed, suppression of TRPC5 resulted in reduction of ATP-induced NFAT activation and NO production, thus promotes hypertrophic response in NRCMs. Although NFAT activation has been long associated with hypertrophic gene

\section{REFERENCES}

Bai, C. X., Kurokawa, J., Tamagawa, M., Nakaya, H., and Furukawa, T. (2005). Nontranscriptional regulation of cardiac repolarization currents by testosterone. Circulation 112, 1701-1710. doi: 10.1161/CIRCULATIONAHA. 104.523217

Balligand, J. L., and Cannon, P. J. (1997). Nitric oxide synthases and cardiac muscle. Autocrine and paracrine influences. Arterioscler. Thromb. Vasc. Biol. 17, 1846-1858. doi: 10.1161/01.ATV.17.10.1846 expression, we speculate that the transient activation of NFAT mediated by TRPC5-dependent $\mathrm{Ca}^{2+}$ entry is not sufficient to induce hypertrophic gene expression in NRCMs.

Because of limitation of the study, we could not determine whether the TRPC5-eNOS axis induced by $\mathrm{P}_{2} \mathrm{Y}_{2} \mathrm{R}$ stimulation in neonatal cardiomyocytes is also applicable to adult cardiomyocytes. As TRPC5-mediated NO signaling requires $\mathrm{IP}_{3}$-mediated $\mathrm{Ca}^{2+}$ release and $\mathrm{IP}_{3}$-mediated $\mathrm{Ca}^{2+}$ signaling is down-regulated in adult cardiomyocytes compared to that in neonatal cardiomyocytes, contribution of TRPC5-eNOS axis might be minor in normal adult cardiomyocytes. Future study using adult cardiomyocytes will be necessary to elucidate the pathophysiological role of TRPC5-eNOS axis in heart.

In summary, we revealed a physiological role of TRPC5 channel in rat cardiomyocytes. TRPC5 functionally couples with eNOS, and activation of TRPC5-mediated NO signaling induced by ATP stimulation negatively regulates $\mathrm{Ca}^{2+}$ /NFAT-dependent hypertrophic response of NRCMs. Purinergic receptors are well accepted as an attractive therapeutic target of age-related cardiovascular diseases (Sunggip et al., 2017), and we suggest the potential benefits of the use of $\mathrm{P}_{2} \mathrm{Y}_{2} \mathrm{R}$ agonists in the prevention of cardiac hypertrophy. Our new finding will provide a new therapeutic strategy for the prevention of pathological cardiac hypertrophy.

\section{AUTHOR CONTRIBUTIONS}

MN supervised and conceived the project. CS, KS, and SO designed the experiments and prepared the manuscript. CS, KS, $\mathrm{SO}, \mathrm{TT}, \mathrm{KN}$, and SM performed the experiments and interpreted the data. MN, AN, and TN-T edited the manuscript.

\section{FUNDING}

This research was funded by grants from Grants-in-Aid for Scientific Research (No. 16H05092 and 16KT0013 to MN) and Scientific Research on Innovative Areas (Research in a Proposed Research Area 'Oxygen Biology' (No. 14430291 to MN) from the Ministry of Education, Culture, Sports, Science; and 'Living in Space' (No. 16H01656 to TN-T), Platform Project for Supporting Drug Discovery and Life Science Research (BINDS) from AMED and Uehara Memorial Foundation (to AN). This study was also supported by the Cooperative Study Program of National Institute for Physiological Sciences (to CS and $\mathrm{SM})$.

Berridge, M. J., Bootman, M. D., and Roderick, H. L. (2003). Calcium signalling: dynamics, homeostasis and remodelling. Nat. Rev. Mol. Cell Biol. 4, 517-529. doi: $10.1038 / \mathrm{nrm} 1155$

Bush, E. W., Hood, D. B., Papst, P. J., Chapo, J. A., Minobe, W., Bristow, M. R., et al. (2006). Canonical transient receptor potential channels promote cardiomyocyte hypertrophy through activation of calcineurin signaling. J. Biol. Chem. 281, 33487-33496. doi: 10.1074/jbc.M605536200

Clapham, D. E., Runnels, L. W., and Strubing, C. (2001). The TRP ion channel family. Nat. Rev. Neurosci. 2, 387-396. doi: 10.1038/35077544 
Colella, M., Grisan, F., Robert, V., Turner, J. D., Thomas, A. P., and Pozzan, T. (2008). Ca2+ oscillation frequency decoding in cardiac cell hypertrophy: role of calcineurin/NFAT as Ca2+ signal integrators. Proc. Natl. Acad. Sci. U.S.A. 105, 2859-2864. doi: 10.1073/pnas.0712316105

Dolmetsch, R. E., Xu, K., and Lewis, R. S. (1998). Calcium oscillations increase the efficiency and specificity of gene expression. Nature 392, 933-936. doi: $10.1038 / 31960$

Dorn, G. W. II, and Force, T. (2005). Protein kinase cascades in the regulation of cardiac hypertrophy. J. Clin. Invest. 115, 527-537. doi: 10.1172/JCI24178

Dubyak, G. R. (1991). Signal transduction by P2-purinergic receptors for extracellular ATP. Am. J. Respir. Cell Mol. Biol. 4, 295-300. doi: 10.1165/ajrcmb/ 4.4.295

Eigenthaler, M., Nolte, C., Halbrugge, M., and Walter, U. (1992). Concentration and regulation of cyclic nucleotides, cyclic-nucleotide-dependent protein kinases and one of their major substrates in human platelets. Estimating the rate of cAMP-regulated and cGMP-regulated protein phosphorylation in intact cells. Eur. J. Biochem. 205, 471-481. doi: 10.1111/j.1432-1033.1992.tb 16803.x

Erlinge, D., and Burnstock, G. (2008). P2 receptors in cardiovascular regulation and disease. Purinergic Signal. 4, 1-20. doi: 10.1007/s11302-007-9078-7

Fiedler, B., Lohmann, S. M., Smolenski, A., Linnemuller, S., Pieske, B., Schroder, F., et al. (2002). Inhibition of calcineurin-NFAT hypertrophy signaling by cGMPdependent protein kinase type I in cardiac myocytes. Proc. Natl. Acad. Sci. U.S.A. 99, 11363-11368. doi: 10.1073/pnas.162100799

Heineke, J., and Molkentin, J. D. (2006). Regulation of cardiac hypertrophy by intracellular signalling pathways. Nat. Rev. Mol. Cell Biol. 7, 589-600. doi: $10.1038 / \mathrm{nrm} 1983$

Hofmann, T., Obukhov, A. G., Schaefer, M., Harteneck, C., Gudermann, T., and Schultz, G. (1999). Direct activation of human TRPC6 and TRPC3 channels by diacylglycerol. Nature 397, 259-263. doi: 10.1038/16711

Kitajima, N., Numaga-Tomita, T., Watanabe, M., Kuroda, T., Nishimura, A., Miyano, K., et al. (2016). TRPC3 positively regulates reactive oxygen species driving maladaptive cardiac remodeling. Sci. Rep. 6:37001. doi: 10.1038/ srep37001

Kitajima, N., Watanabe, K., Morimoto, S., Sato, Y., Kiyonaka, S., Hoshijima, M., et al. (2011). TRPC3-mediated Ca2+ influx contributes to Racl-mediated production of reactive oxygen species in MLP-deficient mouse hearts. Biochem. Biophys. Res. Commun. 409, 108-113. doi: 10.1016/j.bbrc.2011.04.124

Kiyonaka, S., Kato, K., Nishida, M., Mio, K., Numaga, T., Sawaguchi, Y., et al. (2009). Selective and direct inhibition of TRPC3 channels underlies biological activities of a pyrazole compound. Proc. Natl. Acad. Sci. U.S.A. 106, 5400-5405. doi: 10.1073/pnas.0808793106

Kuwahara, K., Wang, Y., Mcanally, J., Richardson, J. A., Bassel-Duby, R., Hill, J. A., et al. (2006). TRPC6 fulfills a calcineurin signaling circuit during pathologic cardiac remodeling. J. Clin. Invest. 116, 3114-3126. doi: 10.1172/JCI27702

Lefroy, D. C., Crake, T., Uren, N. G., Davies, G. J., and Maseri, A. (1993). Effect of inhibition of nitric oxide synthesis on epicardial coronary artery caliber and coronary blood flow in humans. Circulation 88, 43-54. doi: 10.1161/01.CIR. 88.1 .43

Levy, D., Garrison, R. J., Savage, D. D., Kannel, W. B., and Castelli, W. P. (1990). Prognostic implications of echocardiographically determined left ventricular mass in the Framingham Heart Study. N. Engl. J. Med. 322, 1561-1566. doi: 10.1056/NEJM199005313222203

Mayourian, J., Ceholski, D. K., Gonzalez, D. M., Cashman, T. J., Sahoo, S., Hajjar, R. J., et al. (2018). Physiologic, pathologic, and therapeutic paracrine modulation of cardiac excitation-contraction coupling. Circ. Res. 122, 167-183. doi: 10.1161/CIRCRESAHA.117.311589

Michell, B. J., Griffiths, J. E., Mitchelhill, K. I., Rodriguez-Crespo, I., Tiganis, T., Bozinovski, S., et al. (1999). The Akt kinase signals directly to endothelial nitric oxide synthase. Curr. Biol. 9, 845-848. doi: 10.1016/S0960-9822(99)80371-6

Molkentin, J. D., Lu, J. R., Antos, C. L., Markham, B., Richardson, J., Robbins, J., et al. (1998). A calcineurin-dependent transcriptional pathway for cardiac hypertrophy. Cell 93, 215-228. doi: 10.1016/S0092-8674(00)81573-1

Nakayama, H., Wilkin, B. J., Bodi, I., and Molkentin, J. D. (2006). Calcineurindependent cardiomyopathy is activated by TRPC in the adult mouse heart. FASEB J. 20, 1660-1670. doi: 10.1096/fj.05-5560com
Nishida, M., Ogushi, M., Suda, R., Toyotaka, M., Saiki, S., Kitajima, N., et al. (2011). Heterologous down-regulation of angiotensin type 1 receptors by purinergic P2Y2 receptor stimulation through S-nitrosylation of NF-kappaB. Proc. Natl. Acad. Sci. U.S.A. 108, 6662-6667. doi: 10.1073/pnas.1017640108

Nishida, M., Sato, Y., Uemura, A., Narita, Y., Tozaki-Saitoh, H., Nakaya, M., et al. (2008). P2Y6 receptor-Galpha12/13 signalling in cardiomyocytes triggers pressure overload-induced cardiac fibrosis. EMBO J. 27, 3104-3115. doi: $10.1038 /$ emboj.2008.237

Nishida, M., Sugimoto, K., Hara, Y., Mori, E., Morii, T., Kurosaki, T., et al. (2003). Amplification of receptor signalling by $\mathrm{Ca} 2+$ entry-mediated translocation and activation of PLCgamma2 in B lymphocytes. EMBO J. 22, 4677-4688. doi: $10.1093 / \mathrm{emboj} / \mathrm{cdg} 457$

Nishida, M., Watanabe, K., Sato, Y., Nakaya, M., Kitajima, N., Ide, T., et al. (2010). Phosphorylation of TRPC6 channels at Thr69 is required for anti-hypertrophic effects of phosphodiesterase 5 inhibition. J. Biol. Chem. 285, 13244-13253. doi: 10.1074/jbc.M109.074104

Nishimura, A., Sunggip, C., Oda, S., Numaga-Tomita, T., Tsuda, M., and Nishida, M. (2017). Purinergic P2Y receptors: molecular diversity and implications for treatment of cardiovascular diseases. Pharmacol. Ther. 180, 113-128. doi: 10.1016/j.pharmthera.2017.06.010

Numaga-Tomita, T., Kitajima, N., Kuroda, T., Nishimura, A., Miyano, K., Yasuda, S., et al. (2016). TRPC3-GEF-H1 axis mediates pressure overloadinduced cardiac fibrosis. Sci. Rep. 6:39383. doi: 10.1038/srep39383

Numaga-Tomita, T., Oda, S., Shimauchi, T., Nishimura, A., Mangmool, S., and Nishida, M. (2017). TRPC3 channels in cardiac fibrosis. Front. Cardiovasc. Med. 4:56. doi: $10.3389 /$ fcvm.2017.00056

Onohara, N., Nishida, M., Inoue, R., Kobayashi, H., Sumimoto, H., Sato, Y., et al. (2006). TRPC3 and TRPC6 are essential for angiotensin II-induced cardiac hypertrophy. EMBO J. 25, 5305-5316. doi: 10.1038/sj.emboj.7601417

Post, G. R., Goldstein, D., Thuerauf, D. J., Glembotski, C. C., and Brown, J. H. (1996). Dissociation of p44 and p42 mitogen-activated protein kinase activation from receptor-induced hypertrophy in neonatal rat ventricular myocytes. J. Biol. Chem. 271, 8452-8457. doi: 10.1074/jbc.271.14.8452

Sterin-Borda, L., Gomez, R. M., and Borda, E. (2002). Role of nitric oxide/cyclic GMP in myocardial adenosine Al receptor-inotropic response. Br. J. Pharmacol. 135, 444-450. doi: 10.1038/sj.bjp.0704487

Sunggip, C., Nishimura, A., Shimoda, K., Numaga-Tomita, T., Tsuda, M., and Nishida, M. (2017). Purinergic P2Y6 receptors: a new therapeutic target of agedependent hypertension. Pharmacol. Res. 120, 51-59. doi: 10.1016/j.phrs.2017. 03.013

Yeung, K. P. (2013). ATP metabolism as biomarker target for cardiovascular protection. Cardiovasc. Pharmacol. Open Access 2:e118. doi: 10.4172/23296607.1000e118

Yoshida, T., Inoue, R., Morii, T., Takahashi, N., Yamamoto, S., Hara, Y., et al. (2006). Nitric oxide activates TRP channels by cysteine S-nitrosylation. Nat. Chem. Biol. 2, 596-607. doi: 10.1038/nchembio821

Zhu, X., Jiang, M., Peyton, M., Boulay, G., Hurst, R., Stefani, E., et al. (1996). trp, a novel mammalian gene family essential for agonist-activated capacitative $\mathrm{Ca} 2+$ entry. Cell 85, 661-671. doi: 10.1016/S0092-8674(00)81233-7

Zimmermann, H. (2016). Extracellular ATP and other nucleotides-ubiquitous triggers of intercellular messenger release. Purinergic Signal. 12, 25-57. doi: $10.1007 / \mathrm{s} 11302-015-9483-2$

Conflict of Interest Statement: The authors declare that the research was conducted in the absence of any commercial or financial relationships that could be construed as a potential conflict of interest.

The reviewer AA-T and handling Editor declared their shared affiliation.

Copyright (c) 2018 Sunggip, Shimoda, Oda, Tanaka, Nishiyama, Mangmool, Nishimura, Numaga-Tomita and Nishida. This is an open-access article distributed under the terms of the Creative Commons Attribution License (CC BY). The use, distribution or reproduction in other forums is permitted, provided the original author(s) and the copyright owner are credited and that the original publication in this journal is cited, in accordance with accepted academic practice. No use, distribution or reproduction is permitted which does not comply with these terms. 